\section{Revamp governance of Canadian Task Force on Preventive Health Care}

The efficacy of earlier detection of breast cancer by routine screening with mammography was clearly shown in several randomized controlled trials (RCTs) conducted in the 1970 s to 1990 s. $^{1}$ The benefit is understood to come from the ability to treat smaller and earlier-stage screen-detected cancers, the keywords being "earlier" and "treatment." This is logical; no oncologist, given the choice, would opt to treat more advanced disease.

Randomized controlled trials are held up as the gold standard for quality of evidence. But this is true only if the intervention tested in the RCT is consistent with the current question of interest - that is, what is the effectiveness of today's breast cancer screening in women aged 40-74? Although the RCTs on breast screening have provided proof-of-principle of benefit, the screening techniques available at the end of the last millennium were primitive compared with what is used in screening programs today. Since that time, there have been substantial improvements in both screening and therapy. In particular, the detectability of small invasive cancers has improved markedly.

Data from many organized screening programs have shown that women aged 40 and older who avail themselves of screening mammography are from $30 \%$ to $45 \%$ less likely to die of breast cancer than those who are not screened, 2 to 3 times the mortality reduction seen in the RCTs. ${ }^{2,3}$ Much of the increased benefit remained, even after conservative corrections were applied for selfselection bias, a limitation of such observational studies. Recent research has shown that earlier detection also decreases morbidity associated with breast cancer therapy, often reducing the need for mastectomy, axillary dissection and chemotherapy. ${ }^{4}$

To my knowledge, there are no RCTs attempting to evaluate the effect of modern screening combined with modern therapy. And there are unlikely to be any in the future because most scientists in the field are convinced that the question is already answered and that the cost and time delay in conducting another trial with modern screening are not justified. Given the results from RCTs as a baseline, they accept the data from service screening programs that are consistent with a greater level of benefit than shown by the RCTs. Furthermore, it is unlikely that women would now be willing to be randomly assigned to a study arm that did not include screening.

Nevertheless, in $2011^{5}$ and again in its 2018 recommendations, ${ }^{6}$ the Canadian Task Force on Preventive Health Care has chosen to ignore any data on benefit except that from the older RCTs. The task force refuses to consider modern data (some of it coming from recent Canadian studies), placing much emphasis on harms, without making the effort to put those into context with the benefits of reduced mortality and morbidity - a standard approach used in health services research.

The task force's justification against screening women in their $40 \mathrm{~s}$ is based on lower cancer risk in this group. Yet $24 \%$ of life-years lost and $14 \%$ of deaths caused by breast cancer ${ }^{7}$ come from cancers arising over that age range.

Even the title of the recommendations is misleading, limiting the recommendations to “... women not at increased risk ...". The greatest increase in breast cancer risk is in being a woman over 40 . The next greatest attributable risk is having very dense breasts, a double-barrelled risk, because it is also more difficult to detect cancer in the dense breast with mammography - ultrasonography is more accurate. ${ }^{8,9}$ But despite a vast literature, density and ultrasonography are dismissed by the task force.

The recommendations by the task force refer to an approach of "shared decisionmaking between a woman and her health care provider" on whether and when to be screened. A great idea. But has it not always been a patient's right to accept or reject medical advice? It would have been more helpful if the task force had provided accurate information to the physician to guide that advice.

Why does the task force continue to make recommendations that are at odds with the science? The full reason is not clear to me, but the dogma that the only acceptable form of evidence is an RCT, even if that RCT does not really speak to the question - is ludicrous. Physicians and the public should reject these recommendations. Given the limited and cherry-picked consideration of modern data by the Canadian Task Force on Preventive Health Care, physicians cannot rely on its guidelines and have no other choice but to turn directly to the research literature. Health Canada should review and revamp the governance of the task force.

\section{Martin J. Yaffe PhD}

Senior scientist, Physical Sciences, Tory Family Chair in Cancer Research, Sunnybrook Research Institute; professor, Departments of Medical Biophysics and Medical Imaging, University of Toronto; co-director, Imaging Research Program, Ontario Institute for Cancer Research, Toronto, Ont.

- Cite as: CMAJ 2019 February 10;191:E145. doi: $10.1503 / \mathrm{cmaj} .71650$

\section{References}

1. IARC Working Group on the Evaluation of CancerPreventive Interventions. Breast cancer screening. In: IARC Handbooks of Cancer Prevention. 2nd ed. Vol. 15. Lyon (France): International Agency for Research on Cancer; 2014

2. Coldman A, Phillips N, Wilson C, et al. Pan-Canadian study of mammography screening and mortality from breast cancer. J Natl Cancer Inst 2014;106: dju261. doi: 10.1093/jnci/dju261.

3. Broeders M, Paci E. The balance sheet of benefits and harms of breast cancer population-based screening in Europe: outcome research, practice and future challenges. Womens Health (Lond) 2015;11:883-90.

4. Barth RJ Jr, Gibson GR, Carney PA, et al. Detection of breast cancer on screening mammography allows patients to be treated with less-toxic therapy. AJR Am J Roentgenol 2005;184:324-9.

5. The Canadian Task Force on Preventive Health Care. Recommendations on screening for breast cancer in average-risk women aged 40-74 years. CMAJ 2011;183:1991-2001.

6. Klarenback S, Sims-Jones N, Lewin G, et al; for the Canadian Task Force on Preventive Health Care. Recommendations on screening for breast cancer in women aged 40-74 years who are not at increased risk for breast cancer. CMAJ 2018;190:E1441-51.

7. Yaffe MJ, Mittmann N, Alagoz O, et al. The effect of mammography screening regimen on incidencebased breast cancer mortality. J Med Screen 2018; 25:197-204.

8. Berg WA. Current status of supplemental screening in dense breasts. J Clin Oncol 2016;34:1840-1843.

9. Thigpen D, Kappler A, Brem R. The role of ultrasound in screening dense breasts - a review of the literature and practical solutions for implementation. Diagnostics 2018;8:20.

Competing interests: Martin Yaffe has received a grant and nonfinancial support from GE Healthcare outside the submitted work; is a shareholder in Volpara Health Technologies and Izotropic Corporation; is a member of the scientific advisory committee for Izotropic Corporation; and has a patent pending for a density masking index for mammography. 